\title{
Juicio de amigables componedores
}

\author{
Fernando Aguilar \\ Roque J. Caivano
}

\begin{abstract}
SUMARIO
1. Presentación: 1.1. Fuente convencional o legal; 1.2. Denominación; 1.3. Mediación, conciliación y arbitraje; 1.4. La misión de los árbitros de equidad; 1.5 . El silencio del convenio arbitral. 2. La doble misión de los amigables componedores. 3. Las sentencias, los laudos arbitrales de Derecho y los laudos de los amigables componedores. 4. La equidad. 5. Los límites del amigable componedor. 6. La materia arbitrable mediante arbitraje de equidad. 7. Simplificación de los procedimientos. 8. Ejecución. 9. Conclusiones.
\end{abstract}

\section{Presentación}

El libro VI del Código Procesal Civil y Comercial de la Nación (t.o. 1981, LA 1981 B 1472), subtitulado "Proceso arbitral", se divide en tres títulos: el "Juicio arbitral", el "Juicio de amigables componedores" y la "Pericia arbitral" (1). El presente trabajo enfoca el arbitraje de amigables componedores (2). Antes de comenzar a describir sus características principales conviene efectuar algunas precisiones y aclaraciones preliminares.

\subsection{Fuente convencional o legal}

Una primera cuestión introductoria es el origen, la fuente de la que deriva. Como una especie de arbitraje, el de amigables 
componedores es, en principio, de naturaleza convencional y, en consecuencia, nace de un acuerdo de voluntades cláusula contractual o convención autónoma, sea éste expreso o tácito. Sin embargo, debemos anotar que hay casos excepcionales en que el arbitraje viene impuesto por el legislador: en la legislación de fondo, para determinar el precio en la locación de servicios o de obra (art. 1627 CCiv.), para determinar la porción que corresponde al socio industrial en las ganancias producidas por una sociedad civil de capital e industria (art. 1781 CCiv.), para resolver las cuestiones que se susciten sobre la inteligencia de las cartas de crédito o recomendación y las obligaciones que ella importe (art. $491 \mathrm{CCom}$.) o para determinar la comisión o retribución del depositario en el depósito comercial (art. 573 CCom., en este caso, con expresa referencia a "arbitradores"); en la legislación procesal nacional y en otras que reproducen sus normas, para dilucidar liquidaciones complejas o cuentas complicadas en el trámite de ejecución de sentencias (art. 516 CPCCN., pudiendo ser peritos árbitros o amigables componedores); en algunas legislaciones procesales provinciales, para entender en los juicios declarativos generales entre ascendientes y descendientes o entre hermanos consanguíneos (arts. 603 CPCC. Córdoba [LA 1995B 2405] y 417 CPCC. Santa Fe [ALJA 1962 806]).

\subsection{Denominación}

Una segunda cuestión interesante es de naturaleza terminológica, pues para designar a esta clase de arbitraje y para distinguirla de otras suele recurrirse a diferentes denominaciones. El art. $766 \mathrm{CPCCN}$. aclara, en su párr. $2^{\circ}$, que si se hubiese autorizado a los árbitros a decidir la controversia "según equidad" se entenderá que el juicio arbitral es de amigables componedores; y alude a "arbitradores" (3) como otra denominación de los amigables componedores, declarándolos sinónimos. Queda así superada de inicio una cuestión de nombre, ya que la ley asimila el arbitraje según equidad al juicio de amigables componedores, lo que evita de raíz toda controversia doctrinaria sobre el hipotético distinto alcance de ambos términos.

454 Revista Ecuatoriana de Arbitraje 
En el derecho comparado esta clase de árbitros se designan también como amigables componedores (4) o arbitradores (5) , o bien con la más precisa denominación de "árbitros de equidad" (6), o conservando los términos latinos como ex aequo et bono (7), o aludiendo al arbitraje de conciencia (8). Para definir la forma en que resuelven también se utilizan diferentes expresiones: algunas normas, conservando la nomenclatura medieval, disponen que estos árbitros resuelven "a verdad sabida y buena fe guardada", tal como lo hicieron los jueces de paz legos (9); otras (como nuestro CPCCN., art. 769) establecen que el laudo se dictará "según su saber y entender", o conforme a su "leal saber y entender" (10) ; por fin, no faltan las que directamente refieren a la equidad o a la conciencia como soportes de su decisión (11).

\subsection{Mediación, conciliación y arbitraje}

Relacionado con la cuestión terminológica, conviene hacer notar que, en un sentido literal, la locución "amigables componedores" pareciera sugerir erróneamente que estamos en presencia de un método que propicia una composición amigable de intereses encontrados, un acuerdo entre las partes, método que es hoy designado preferentemente como "mediación" o "conciliación". Sin embargo, el juicio de amigables componedores es un arbitraje y no una negociación, género al que pertenecen tanto la conciliación (12) como la mediación (13). Las diferencias entre estos últimos y el arbitraje de amigables componedores son sustanciales: el mediador o el conciliador tienen como misión intentar que las partes, a través de un proceso no adversarial, pongan fin al conflicto mediante un acuerdo mutuamente satisfactorio. El amigable componedor es un árbitro, y, como tal, un verdadero juez, cuyo cometido no es buscar un acuerdo sino adoptar una decisión sobre las pretensiones expuestas por las partes en el proceso adversarial, que, aunque más informal, tiene las características propias de un juicio (14). El mediador y el conciliador carecen de todo poder de decisión, y en cualquiera de estos procesos la solución del conflicto depende entera- 
mente de la voluntad de las partes; ese poder jurisdiccional es de la esencia del amigable componedor (como lo es de cualquier clase de árbitro), de modo que en el juicio de amigables componedores el resultado recae íntegramente sobre el árbitro, quien dicta una verdadera sentencia (15).

\subsection{La misión de los árbitros de equidad}

Aparte de la cuestión de su nombre, el arbitraje de equidad no ha sido interpretado con uniformidad por los autores que abordaron el tema, y la jurisprudencia no ha determinado con precisión la órbita de poder del amigable componedor, ni su distinción frente a los árbitros de derecho (iuris) o a los jueces. Nuestra postura es que el amigable componedor o árbitro de equidad (tal como hoy se lo entiende y como conviene definirlo para evitar equívocos) tiene dos libertades características de las que no gozan los restantes jueces, ya sean árbitros de derecho o estatales. Por un lado, pueden establecer normas procesales más simples y flexibles; y por el otro, pueden decidir apartándose del derecho aplicable, salvo cuando se trate de normas de orden público que resulten indisponibles para las partes (16). Pero la esfera de su jurisdicción tiene su propio límite, porque aun gozando de mayor discrecionalidad que los restantes jueces o árbitros iuris, los amigables componedores deben respetar principios esenciales a todo juicio, tales como el principio de bilateralidad o contradictorio, de igualdad de las partes y de ausencia de arbitrariedad.

El convenio que establece la misión para el árbitro de actuar como árbitro de equidad o dictar su sentencia "según su leal saber y entender" (art. 769 CPCCN.) mantiene su utilidad en el derecho contemporáneo. Permite a las partes minimizar el riesgo de enfrentar una impugnación del laudo basada en defectos procesales, o fundada en ignorancia o error de derecho, incrementando de este modo la eficacia del arbitraje. Por otra parte, la solución en equidad puede contemplar la situación de las par-

Revista Ecuatoriana de Arbitrafe 
tes afectada por hechos imprevisibles o inevitables en mejor medida que las soluciones brindadas por la doctrina de la fuerza mayor, o la llamada "teoría de la imprevisión" (art. 1198 in fine CCiv.), y en el caso de contratos internacionales dota al litigio de un marco de referencia cuando varios sistemas jurídicos nacionales tienen vocación de ser aplicados en pie de igualdad pero conllevan soluciones y consecuencias distintas, o aun contradictorias (17).

\subsection{El silencio del convenio arbitral}

Para concluir estas breves notas introductorias debe señalarse que en el CPCCN. el arbitraje de equidad se encuentra previsto como norma de reserva para el caso en el que las partes han guardado silencio en su convención sobre si se trata de un arbitraje iuris o de amigables componedores (art. $766 \mathrm{CPCCN}$.). El principio inverso es el que actualmente prevalece en la legislación comparada (18) y es hoy adoptado en la mayor parte de las instituciones de arbitraje más frecuentemente utilizadas (19), entendiéndose que si las partes nada dijeron al respecto, ha de presumirse que optaron por un arbitraje de derecho (iuris) (20).

\section{La Doble Misión de los Amigables Componedores}

El concepto de amigable componedor implica una doble misión para el árbitro, ya que éste se encuentra sujeto a dos tipos de reglas. Las más importantes y esenciales se refieren a los fundamentos de su laudo o sentencia. Además existen reglas tendientes a la simplificación del procedimiento arbitral.

$\mathrm{El}$ art. $769 \mathrm{CPCCN}$., aplicable en ausencia de pacto expreso, incluye ambas situaciones, ya que establece: 
"Los amigables componedores procederán sin sujeción a normas legales, limitándose a recibir los antecedentes 0 documentos que las partes les presentasen, a pedirles las explicaciones que creyeren convenientes, y a dictar sentencia segün su saber y entender".

La parte $1^{\mathrm{a}}$ del artículo se refiere a las consecuencias procesales que derivan de pactar arbitraje de amigable composición. La segunda, y más importante, es la que, en sustancia, lo caracteriza. En esta última, aun bajo la escueta referencia al "leal saber y entender", la ley procesal alude inequívocamente al efecto principal de un acuerdo de las partes sometiéndose a amigables componedores: la voluntad común de apartarse de las normas legales que resulten aplicables al caso, para hallar una solución equitativa a su controversia. Precisamente en ello radica la esencia de la amigable composición: la autorización que las partes conceden al árbitro para que éste decida según su conciencia, su sentido de equidad y su conocimiento leal del caso.

El artículo transcripto sigue un orden temporalmente lógico, al enunciar en primer término las notas propias al proceso. En nuestro análisis, sin embargo, alteraremos este orden debido a que consideramos como esencial la facultad del árbitro derivada del acuerdo de partes para decidir el litigio apartándose de las normas jurídicas aplicables al caso, antes que la facultad meramente instrumental de atenerse a un procedimiento simplificado en extremo, que como veremos, aunque suele ser natural en esta clase de arbitraje, puede ser acotada por las partes.

Una de las cuestiones más debatidas en orden a la amigable composición es, precisamente, la que estamos tratando aquí. Por un lado, muchos se preguntan si es acaso posible fallar extra legem, es decir, si el derecho permite resolver un conflicto patrimonial y dotar a esa decisión de la fuerza de la cosa juzgada cuando esa decisión no reposa sobre criterios jurídicos. Pareciera, a primera vista, que la vocación totalizadora del derecho tiende a convertir en jurídico aquello que en principio no lo 
era. Aunque nadie puede negar la posibilidad de que las partes resuelvan los conflictos que involucran derechos disponibles del modo que deseen pues ésa es, justamente, la condición básica de esos derechos, suele pensarse que en tales supuestos la solución tiene un alcance limitado a las partes y jamás podría ser reconocida por el sistema jurídico. De esta manera la decisión basada en el simple leal saber y entender de una persona lega en temas jurídicos quedaría reducida a un mero consejo quizás con fuerza obligatoria moral por el respeto que despierta y la autoridad intelectual del tercero escogido por las partes, pero nunca susceptible de ejecución forzada a través del sistema judicial.

Las consideraciones precedentes pueden no sorprender demasiado a los abogados habituados a los silogismos de la ley escrita. No es extraño que la idea de hallar una solución jurídicamente vinculante a un pleito que afecta derechos de naturaleza jurídica y sustancia económica sin apoyo en norma legal de especie alguna genere cierto rechazo o aversión entre los colegas. Aun aceptando que tal cosa puede ser posible, otros la juzgan inconveniente y peligrosa (21).

Sin embargo, la perspectiva del arbitraje comercial internacional facilita la comprensión de los alcances de este modo de arbitraje, cuya motivación suele encontrarse en varios factores. Los hombres de negocios hallan apropiado el arbitraje de equidad para resolver sus conflictos porque desconfían del formalismo frecuentemente excesivo del derecho: acostumbrados a cerrar contratos fundamentalmente sobre la base de la buena fe, quieren que la solución de los conflictos que se originan de ellos se encuentre basada también en la buena fe, antes que en una interpretación literal de un texto normativo. Otras veces este modo de arbitraje se escoge porque las prestaciones emergentes del contrato exceden el ámbito de vigencia de las leyes nacionales, y, en estas condiciones, para evitar la necesidad de determinar un sistema jurídico nacional que gobierne el contrato entre los varios posibles, se opta por un arbitraje de amigables componedores que permite al árbitro hallar la solución equitativa con- 
siderando varias leyes nacionales a la vez desde la perspectiva de lo que fue la común intención de las partes (22). También resulta una herramienta útil en los contratos de largo plazo, cuando las partes buscan un refugio que las proteja de cambios en la legislación que alteren la ecuación contractual en beneficio de una parte y con perjuicio de la restante, así como respecto de cambios sustanciales en las condiciones de mercado, como lo son aquellos que resultan de nuevos desarrollos tecnológicos. Finalmente, también resulta de utilidad cuando la controversia tiene aspectos técnicos tan complejos que las normas generales del derecho de las obligaciones no aportan todos los elementos necesarios para comprender cabalmente la discusión.

\section{LAS SENTENCIAS, LOS LAUDOS ARBITRALES DE DERECHO Y LOS LAUDOS DE LOS AMIGABLES COMPONEDORES}

Un punto de partida obligado para aprehender la naturaleza del instituto en análisis es confrontar los poderes de los jueces y árbitros iuris frente a la jurisdicción de los árbitros de equidad.

$\mathrm{El}$ art. 34.4 CPCCN. establece para los jueces el deber de fundar toda sentencia, aun interlocutoria, bajo pena de nulidad, respetando la jerarquía de normas vigentes y el principio de congruencia. Este deber es extensivo a los árbitros de derecho (iuris), ya que las normas sobre nulidades procesales son de aplicación subsidiaria al arbitraje de derecho (art. 761 CPCCN.).

Los fundamentos del laudo resultante del arbitraje de equidad pueden no expresarse si las partes así lo acordaron. Pero lo característico es que cuando son explicitados en el laudo, los fundamentos pueden consistir en una explicación de las razones de equidad que motivaron la solución alcanzada, con independencia de la ley aplicable al caso concreto. Al pactar el arbitraje de amigables componedores las partes están autorizándolos a 
justificar de ese modo su decisión y obligándose a respetar el honesto saber y entender de los árbitros. Por lo demás, considerando que los árbitros podrían ser personas carentes de versación jurídica, no sorprende que las partes los dispensen de invocar normas jurídicas como apoyo a la solución hallada. Si son legos en Derecho, los fundamentos jurídicos que pudieran elucubrar no debieran revestir mayor interés; $y$ aun siendo letrados, si se les atribuyó la condición de amigables componedores es porque las partes privilegiaron su sentido de equidad por sobre su saber jurídico.

Esa dispensa tiene una importante significación no siempre cabalmente comprendida por quienes pactan la amigable composición y considerables efectos.

En relación con su significado, pactar el sometimiento al juicio de amigables componedores implica mucho más que prorrogar la competencia de los tribunales judiciales: supone la voluntad de las partes de excluir no sólo la jurisdicción judicial sino incluso el sistema de toma de decisiones propio de ese fuero. Entraña el deseo de las partes de evitar la solución "legal" y, en cambio, sujetar el resultado del caso al recto juicio de una persona, permitiéndole despojarse de convencionalismos o consideraciones puramente legales (23).

En cuanto a sus efectos, el más trascendente es que el laudo se torna prácticamente invulnerable por alegados errores de derecho o defectos en la fundamentación legal que de otro modo podrían esgrimirse como causal de revisión. El laudo ganará, así, en eficacia. Si bien la recta doctrina sostiene que el error de derecho no es revisable por el tribunal judicial cuando las partes han renunciado a apelar e interponer otros recursos para impugnar el laudo (24), la experiencia demuestra que muchas veces el juez tiende a justificar su intervención y controlar la solución de fondo si la considera equivocada, aunque esté de ese modo excediendo los límites de su jurisdicción revisora, por haber mediado una renuncia a la instancia judicial. Al carecer de un razona- 
miento que pueda ser escrutado jurídicamente, el laudo de los amigables componedores reduce esta tentación correctora del juez (25).

La situación del abogado designado "árbitro arbitrador" plantea una situación que merece atención. Se ha dicho que el abogado, por serlo, no puede desprenderse del bagaje jurídico adquirido durante su esforzado paso por alguna escuela o facultad de Derecho. De ello pretende deducirse que su "leal saber y entender" debe necesariamente coincidir con la ley aplicable al caso que él mismo no podría ignorar. Así, dice Palacio: "Esta expresión normativa no debe empero entenderse en el sentido de que los arbitradores estén facultados para prescindir de aplicar las normas jurídicas y, por ende, la Ley Fundamental, de modo que si el tribunal se compone de abogados y de otras personas carentes de ese título, la decisión de las causas debe tener como fundamento como se expuso en el Prólogo del Reglamento de Arbitraje de la Bolsa de Comercio (26) en 'el leal saber y entender de letrados', vale decir que deberán integrarse con el saber y entender de hombres versados en derecho". En similar sentido dice Anaya: "Es obvio que [el] leal saber no puede dejar de lado el derecho y su muletn de equidad cunto los amigables componedores son abogados" (27).

Esta interpretación, entendida en su literalidad, tendría el sentido de vaciar de contenido a la cláusula arbitral cuando las partes eligen como amigable componedor a un abogado o licenciado en Derecho. Bajo este razonamiento, la labor del árbitro de equidad quedaría equiparada a un arbitraje iuris, con la única diferencia de que aquél quedaría dispensado de invocar en su fallo la ley aplicable al caso; en otras palabras, debería aplicar la norma correcta aunque sin decirlo expresamente. En nuestra opinión, la presunción implícita en ese razonamiento anula la esencia misma de la amigable composición y, sobre todo, aniquila y priva de todo sentido y efecto a la declaración de voluntad común de las partes, que, precisamente, consistió en autorizar al árbitro a decidir en equidad o como amigable componedor.

Revista Ecuatoriana de Arbitraje 
Por otro lado, el árbitro podrá ser conocedor del derecho sustancial vigente en el lugar en el que se encuentra habilitado a ejercer la profesión de abogado; sin embargo, el arbitraje internacional es algo más complejo, porque las partes en un contrato internacional pueden válidamente elegir el derecho aplicable al contrato, que no necesariamente será aquel respecto del cual posea versación el árbitro. Aun sin mediar elección, las normas de conflicto de leyes pueden significar que, reenvío mediante, resulte aplicable un sistema jurídico distinto del conocido por el abogado (28). Es posible que la sede del arbitraje resulte distinta de la jurisdicción en la que el abogado obtuvo su diploma, y su formación y hábitos forenses podrían resultar un escollo que deberá superar, antes que una ventaja.

En realidad, si un profesional del Derecho acepta constituirse en árbitro de equidad, debe velar por no exceder su misión. Y como su competencia surge de los términos de la cláusula arbitral, si los mismos son claros en cuanto a eximirlo de aplicar la ley vigente de un país determinado, no se ve por qué motivo traicionaría este cometido. Sin embargo, la experiencia indica que con frecuencia la solución equitativa es también la solución al caso contenida en el sistema o por alguno de los sistemas jurídicos, si fueran más de uno, con vocación para ser aplicables. Pero en tal supuesto la coincidencia entre la solución jurídica y la solución de equidad no resulta de aplicar la norma jurídica, sino del sentido de la equidad que anida en la honesta conciencia del árbitro. Que además dicha solución sea propiciada por alguno de los sistemas jurídicos positivos que rigen las relaciones que motivan el conflicto es una feliz coincidencia que serviría tal vez como una justificación obiter dicta, pero que no cambia las cosas, y la omisión de su mención en los fundamentos no invalida ni debilita el laudo. De lo que se deriva que cuando el amigable componedor cita la solución legal en apoyo de su decisión de equidad no está con ello apartándose de su cometido, sino haciendo notar la coincidencia de ambas soluciones. 
Recapitulando: salvo dispensa expresa de las partes, el laudo de amigables componedores debe exteriorizar las motivaciones que lo justifican y explican, porque las partes tienen el derecho de conocer cuál es el fundamento en equidad que llevó al juzgador a privilegiar una solución sobre la gama de restantes soluciones posibles. Pero es indudable que no requiere fundarse en Derecho (aunque el ordenamiento puede invocarse como refuerzo de su decisión). Allí reside la diferencia esencial entre una sentencia judicial y el laudo de árbitros iuris frente al laudo de amigables componedores.

\section{LA EQUIDAD}

Se ha dicho que los amigables componedores deciden en equidad. Ello implicaría, en un trabajo como el presente, la necesidad de intentar dotar de significado concreto a este concepto. Sin embargo, reconociendo de antemano la imposibilidad de hacerlo en términos precisos (29), nos limitaremos apenas a formular algunas reflexiones que puedan servir para comprender la naturaleza de las decisiones de los amigables componedores (30).

Los autores que enfrentan este problema suelen rápidamente retroceder al Derecho romano y, en este vuelo a través de los siglos, hasta se remontan a Aristóteles. Con ello la tarea se torna realmente ardua (31). Algunos se animan a sistematizar sus significados, encontrando que la palabra "equidad" puede referirse, indistintamente, a: i) lo fundamentalmente justo; ii) la sentencia justa basada en una interpretación razonable de la ley; y iii) el criterio en el que deben inspirarse las facultades discrecionales del juez (32). Otros, inclusive, encuentran aplicaciones y conceptos específicos de la equidad en los distintos ámbitos del Derecho (33). Aunque es cierto como suele decirse que reconocer la equidad es más fácil que definirla, a nuestros fines podemos concebirla como una fórmula que indica al juez que debe 
procurar una buena solución, "la mejor solución que el caso admita, aumque no sea la solución que pueda darse a todos los casos" (34) , $\mathrm{ni}$ agregamos la solución que corresponda por aplicación de la ley.

En términos más amplios, puede citarse la opinión de un importante jurista peruano para quien

"la equidad no es una mera emoción de justicia, no es un concepto vago o impreciso que no admite un desarrollo racional. La equidad, cuando menos desde la perspectiva moderna, es algo muy objetivo: la voluntad o intención de las partes. Esta voluntad debe ser aprehendida no solamente en cuanto lo que fue la expresión literal de ella a través del contrato sino persiguiendo su sentido profundo, el espíritu que animó a las partes y, más aún, procurando establecer no solamente lo que esa voluntad fue en los hechos sino también lo que esa voluntad o intención habría sido si ambas partes tuvieran o hubieran podido tener la misma información sobre el negocio y las mismas habilidades y poderes de negociación" (35).

Tratándose del derecho de los contratos, que es aquel en el que se manifiesta la cláusula arbitral con mayor frecuencia, la equidad se ve impregnada de sustancia económica y puede ligarse al interés patrimonial recíproco que tuvieron las partes al contratar, o a los riesgos patrimoniales que cada una asumió en vista de la prestación prometida por la otra parte, e inherentes a la naturaleza propia del contrato. De modo que ningún juzgador, sea juez, árbitro de derecho o amigable componedor, puede resolver con justicia un diferendo contractual sin tener en cuenta esas premisas (36). Así, se ha dicho que

"El amigable componedor no está constreñido a ceñirse al derecho, en la estrictez de la norma vigente sino en su correspondencia con la equidad y la justicia que interpreta según su leal saber y entender. Pueden enunciarse, en tal sentido, algunos criterios objetivos de su función especialmente constatables en laudos dictados en controversias internacio- 
nales tales como el respeto a una presunción de equidad en las cláusulas contractuales, la aplicación del principio de confianza y buena fe y el seguimiento de una regla de experiencia característica que consiste en la búsqueda de una solución que resulte aceptable para ambas partes sin comprometer sus posibles negocios futuros" (37).

Si los jueces estatales que dictan sentencia aplicando la ley positiva pueden resolver cualquier caso dudoso por aplicación de principios generales no contenidos expresamente en normas jurídicas positivas, cabe preguntarse cuál sería entonces la diferencia con los amigables componedores. Esta diferencia surge nítida a poco de que se repare en que la directiva del art. 16 CCiv. únicamente es admisible si el texto de la ley genera alguna duda en su intérprete. Por ello cuando el texto de la ley es claro los jueces y los árbitros de derecho deben aplicar la ley tal como ha sido escrita, y siendo el contrato la ley de las partes, deben aplicar las cláusulas contractuales respetando la voluntad de las partes en ellas expresada (art. 1197 CCiv.; Reglamento CCI., art. 17.2). En cambio, los amigables componedores, cualquiera sea su formación profesional, se encuentran autorizados por las partes para prescindir de la ley o leyes de posible aplicación y para resolver el pleito mediante la solución que les dicta su leal saber y entender, incluyendo la posibilidad de adecuar las obligaciones emergentes del contrato aplicando principios de equidad.

$\mathrm{Si}$ bien se acepta que en el arbitraje de equidad el árbitro puede apartarse flexibilizando la ley aplicable, la posibilidad para los amigables componedores de adaptar los contratos genera cierta controversia en la doctrina internacional (38). Esta adecuación, sin embargo, no debe conducir a la transformación de un contrato en otro, es decir, a frustrar la voluntad de las partes imponiéndoles términos o riesgos que lo desnaturalizarían. Los criterios de adecuación del contrato deben intentar identificar, sobre la base del contrato y de la conducta posterior de las partes, cuál hubiera sido el acuerdo equitativo de haber ambas 
conocido las nuevas circunstancias al tiempo de contratar (39). La adaptación del contrato incluye la posibilidad de llenar las lagunas o suplir omisiones, aunque no incluye la de crear nuevas obligaciones que no se encuentren expresa o tácitamente previstas en el contrato, o que no reflejen la intención de las partes $(40)$.

La misión esencial del amigable componedor no es, pues, apenas una "flexibilización" de la ley aplicable sino una autorización de las partes para que el árbitro se aparte por completo de la ley que de otro modo sería aplicable (41). De allí que cuando el amigable componedor resuelve el caso alcanzando igual resultado que el establecido por la ley o las leyes aplicables situación que resulta frecuente debe fundar sus conclusiones en equidad con especial prudencia, ya que resulta del acuerdo de partes que la voluntad de las mismas fue apartarse de la ley vigente para resolver su conflicto.

Puede preguntarse si estos principios generales del derecho coinciden con la llamada nueva Lex Mercatoria o Derecho Internacional de las Transacciones Comerciales (42), y si ésta a su vez plasma los usos y costumbres de los comerciantes. En realidad, cabe mencionar que la Lex Mercatoria se encuentra imbuida de equidad, pero es posible hacer una distinción de género a especie, pues la equidad es la fuente más fecunda de la Lex Mercatoria (43). Un árbitro iuris que funde su laudo en los principios generales del derecho y teniendo en consideración las circunstancias del caso (art. 16 CCiv.), o los principios de la Lex Mercatoria, debe en primer lugar razonar los motivos por los que considera que la ley aplicable a la controversia lo autoriza a encontrar la solución basándose en tales principios generales con preferencia a otras leyes aplicables; y en segundo lugar debe constatar la existencia de tales principios (44). Un amigable componedor no necesita demostrar la oscuridad de la ley ni la existencia de principios generales de derecho que soporten su razonamiento, aunque, naturalmente, tiene que explicar el sentido de equidad de su decisión y las motivaciones que la sustentan. 
Dicho esto, cabe observar que en nuestro derecho la ley positiva se refiere en contadas ocasiones a la equidad en forma directa. Ello puede encontrarse con nitidez en los arts. 515, 1071 bis y 1198 CCiv. Los arts. 656 y 954 son también citados como aplicación de principios de justicia equitativa (45), aun cuando esta palabra no es incluida en su texto. Finalmente, en tiempos recientes la legislación emergente de la crisis política y económica de 2002 estableció el concepto del "esfuerzo compartido" (art. 11 Ley de Emergencia 25561 [LA 2002 A 44]) y remitió a la equidad (art. 8 decreto 214/2002 [LA 2002 A 86]) para resolver los problemas que la emergencia proyectaba sobre los contratos celebrados en moneda extranjera. En materia comercial, el art. 218 inc. 3 CCom. remite a las "reglas de la equidad" para decidir el alcance de las cláusulas de un contrato cuando siendo necesario interpretar el mismo, una cláusula es susceptible de dos sentidos y ninguno de ellos priva de validez el acto, siempre que el resultado alcanzado por aplicación de la equidad no lo desnaturalice ("...que más convenga a su naturalezn") (46).

En los contados casos en los que, de no mediar convención de arbitraje, la ley aplicable remite expresa y directamente a la aplicación de la equidad, la facultad del amigable componedor coincide con la jurisdicción de los jueces o árbitros de derecho, salvo que tratándose de amigables componedores, según ya fuera dicho, no es necesario que el intérprete se encuentre frente a una cláusula contractual oscura y no necesariamente deberá aplicar la ley del país de la sede del arbitraje o la de aquel en donde se pretende ejecutar el laudo si se trata de un arbitraje internacional.

La remisión a principios de equidad que hacen los Códigos de fondo por lo general contempla casos en los que la ley resulta impotente para señalar un criterio exacto de distribución de riesgos entre dos partes en un contrato, debido a que las circunstancias fácticas o las características propias de una relación jurídica individualizada no han permitido su encuadramiento anticipado mediante una formulación genérica, y dichos factores

468 Revista Ecuatoriana de Arbitraje 
juegan un rol preponderante en la elaboración de la solución más justa, 0 , si se prefiere, que mejor preserve la paz social.

\section{Los LÍMITES DEL AMIGABLE COMPONEDOR}

El amigable componedor encuentra limitada su discreción, en tanto el laudo es el resultado buscado a través de un proceso contradictorio que para ser válido y ejecutable debe cumplir ciertas condiciones mínimas impuestas por el derecho vigente. En el ámbito del arbitraje internacional, las normas que imponen esas condiciones son tanto las del lugar de la sede del arbitraje cuyos tribunales son los que usualmente controlan la validez mediante recursos o acciones de nulidad como las del lugar donde aquél pretenda ser ejecutado con valor de sentencia judicial, cuyos tribunales controlan su ejecutabilidad, a través de los procedimientos previstos para el reconocimiento y ejecución de laudos extranjeros.

Esas limitaciones se refieren, por un lado, a la fundamentación misma del laudo y, por el otro, al marco procesal en que se desenvuelven.

En cuanto a las primeras debe enfatizarse que por más libre que se encuentre para no aplicar derecho, un amigable componedor no podría decidir el caso echando al aire una moneda (método que, sin embargo, acepta nuestro derecho positivo para resolver diferencias patrimoniales: art. 2068 CCiv.) (47). Tampoco podría hacerlo utilizando un criterio puramente caprichoso (que Anaya desmerece como "discrecionalidad subjetiva": ver Anaya, Jaime L., "Equidad y amigable composición" cit.). Resolver el caso según equidad, por fin, no determina necesariamente una decisión "salomónica" por la cual se parta al medio el objeto del litigio y se otorgue a cada uno la mitad de lo que pide. El amigable componedor puede en rigor, debe otorgar el $100 \%$ de su pretensión a una parte si encuentra que su oponente nada tiene de razón (48). 
En cuanto a las limitaciones referidas al encuadre procesal, los amigables componedores no pueden apartarse de los términos en que quedó trabada la litis (al fin y al cabo, el juicio de amigables componedores, aunque con menor rigor formal que otros, es un juicio), ni conceder a una parte más de lo que pidió. De hecho, laudar ultra o extra petita es uno de los escasos motivos de los cuales puede derivarse la nulidad de su laudo (art. 771 CPCCN.). Tampoco puede, sin desnaturalizar su misión y poner en riesgo la validez del laudo, apartarse de los hechos probados que resulten de la causa.

Los árbitros de equidad deben, en fin, actuar con buena fe, ser honestos e independientes, dar a las partes igual oportunidad de exponer su caso y actuar sin engaño.

Está claro, pues, que la solución en equidad no puede apartarse de aquellas normas que se imponen a la autonomía de voluntad de las partes por ser de orden público. Ello incluye las normas procesales del lugar de la sede, lex arbitri, que participen de esta característica. A ello sin duda alude Anaya (Anaya, Jaime L., "Equidad y amigable composición" cit.) cuando refiere a la necesidad del amigable componedor de estudiar la ley. Sin embargo, no es lo mismo investigar un sistema jurídico nacional aplicable a fin de dar con la solución justa del litigio que buscar si existen en el sistema jurídico aplicable al caso normas de orden público, ya sea de naturaleza procesal o de fondo, que inhiben el acuerdo de arbitraje o limitan el ámbito de decisión del amigable componedor. Es que una vez satisfecho de la validez de la cláusula arbitral correspondiente, el "árbitro arbitrador", en la esfera de sus facultades no restringida por normas específicas indisponibles para las partes, tendrá amplia facultad para decidir el caso según su leal saber y entender, y sin fijarse en lo que disponen las restantes leyes que serían aplicables de no mediar el acuerdo.

Un caso especial de normativa de orden público resulta de los sistemas de protección de ciertas personas o categorías, como 
lo son las normas de defensa de los derechos del consumidor (49). En estos casos, en tanto el derecho de la parte protegida por la ley no resulte conculcado, no existe inconveniente en que los conflictos derivados de las relaciones de consumo puedan ser resueltos mediante arbitraje de amigables componedores. De hecho, ése es un campo en que el arbitraje ha demostrado ser particularmente eficaz, como lo comprueban las experiencias de España y de la Argentina (50).

\section{LA MATERIA ARBITRABLE MEDIANTE ARBITRAJE DE EQUIDAD}

En cuanto al ámbito material de las controversias susceptibles de ser solucionadas mediante arbitraje de equidad, fuera de lo ya expuesto, el árbitro iuris y el amigable componedor gozan de exactamente las mismas facultades, aunque, vale la pena aclararlo, la competencia dentro de dicho ámbito va a encontrarse limitada en concreto por lo pactado en la correspondiente convención arbitral (art. 766 CPCCN.), y los términos en que se haya trabado la litis, de resultas de las presentaciones de las partes.

Muy lejos en el tiempo ha quedado alguna antigua teoría carente de todo asidero que postulaba la imposibilidad de los amigables componedores de resolver "cuestiones de derecho" (51), limitando su campo a las "cuestiones de hecho" (52).

La arbitrabilidad de una determinada materia o cuestión no depende de la naturaleza del arbitraje escogido por las partes, sino de la naturaleza de los derechos involucrados en ella. El ámbito natural del arbitraje son los derechos disponibles (susceptibles de transacción, conforme a la fórmula elegida por nuestro legislador en los arts. 736 y 737 CPCCN.). Siendo disponible el derecho que subyace en la controversia, la materia es arbitrable, esto es, puede ser decidida por árbitros, sean éstos de derecho o de equidad; careciendo de esa condición, no es arbitrable para ninguno de ellos. 
Con todo, alguna duda puede plantearse en torno a la posibilidad de los amigables componedores, incluyendo aquellos legos no versados en derecho, de declarar la inconstitucionalidad de una ley. Tomando en cuenta que, conforme al sistema judicial argentino, el control ejercido por el Poder Judicial sobre la constitucionalidad de las leyes es difuso, y no se encuentra centralizado en un órgano dotado de dicha función, la doctrina y la jurisprudencia se han inclinado por admitir este poder, bien que sujetándolo a las mismas restricciones que sufren los jueces ordinarios. Los principales argumentos se basan en considerar que los árbitros, aun los amigables componedores, ejercen jurisdicción al igual que los jueces, y por lo tanto no cabe efectuar distinciones (53).

Si bien se mira, el debate únicamente reviste utilidad referido a las normas de orden público, ya que la aplicación de aquellas normas que consagran derechos disponibles por las partes puede ser obviada por los amigables componedores sin necesidad de declarar formalmente su inconstitucionalidad. En tal caso, esta declaración parecería superflua, pues, en definitiva, ella no tiene en nuestro sistema de control constitucional más efecto que permitir al juez dejar de aplicar la norma reputada inconstitucional. Al juez o al árbitro de derecho, por estar obligados a aplicar las normas vigentes, les resulta imprescindible declarar la incompatibilidad de alguna de ellas con la Constitución para dejar de aplicarlas. Los amigables componedores no necesitan tal declaración, toda vez que pueden por la propia naturaleza de su misión prescindir de la invocación de la norma o de la fundamentación legal de su decisión.

Distinto es el caso de las normas de orden público, que se imponen a las partes aun cuando medie cláusula de arbitraje de equidad si resulta aplicable al fondo de la controversia el Derecho argentino. En este caso cabe preguntarse si en virtud de la restricción establecida por el art. 737 CPCCN. puede considerarse la cuestión de la constitucionalidad de las leyes como una materia no transigible o no arbitrable y, por consiguiente, extra- 
ña a la jurisdicción arbitral y al ámbito de las facultades del amigable componedor. La doctrina más caracterizada y algunos fallos avalan esta facultad, aunque la cuestión dista de ser pacífica. En nuestra opinión, la solución debe buscarse en la cláusula arbitral y el respectivo contrato. En concreto, si la cláusula es lo suficientemente amplia, y la cuestión controvertida podría ser objeto de una transacción, los árbitros amigables componedores deberán analizar aquellas disposiciones aplicables que por ser de orden público no pudieron ser derogadas por las partes, $y$, consecuentemente, la concordancia de éstas con la norma de jerarquía constitucional. Ello, sin embargo, merecería una fundamentación expresa, que no sería requerida para las cuestiones no jurídicas resueltas, ni para las cuestiones jurídicas regidas por leyes supletorias o que las partes pudieren decidir no observar.

En suma, si los amigables componedores deben aplicar las normas de orden público por ser éstas indisponibles e insoslayables, deben contar también con la facultad de declararlas inconstitucionales si dieran lugar a cualquier conflicto con la Constitución Nacional. Si la única manera de construir un fallo equitativo fuera prescindiendo de una norma que no pueden soslayar, por ser de orden público, no tendrán más alternativa que declarar su inconstitucionalidad (54).

\section{SimplificaCión DE LOS PROCEDIMIENTOS}

Los amigables componedores pueden flexibilizar y simplificar los pasos formales necesarios para llegar al laudo. A falta de acuerdo se encuentran autorizados para decidir sobre la sola base de la documentación o de las explicaciones que pueden requerir directamente a las partes o a terceros (55). Éste es un rasgo distintivo que caracteriza a los árbitros arbitradores, lo que incluye, naturalmente, la mayor amplitud de criterio con la que les es permitido valorar la prueba que las partes hubieran producido. 
Para algunos la falta de sujeción a formas procesales rígidas incrementa peligrosamente el ámbito discrecional del amigable componedor para llevar adelante el procedimiento. Para nosotros, en cambio, ello insufla al juicio arbitral una saludable bocanada de aire puro. Sobre todo si se lo compara con el ámbito asfixiante por su rigidez del procedimiento judicial, donde la igualdad de trato a las partes se ha convertido en un hipergarantismo que hace prevalecer la extrema severidad de las formas rituales, con total olvido de la finalidad última del proceso (56). En tal sentido, el apego dogmático a las formas rigurosamente simétricas entre los contendientes frecuentemente determina que la verdad material y el derecho sustancial sucumban a meros errores o accidentes procesales, que en sí mismos carecerían de toda consecuencia para la contraparte, y que los abogados abusen de chicanas y vericuetos procesales para ganar un caso que en justicia no los favorece, o para eternizar el proceso.

Dicho ello, sin embargo, cabe recordar que el amigable componedor encuentra dos límites muy claros en esta materia. Por un lado, su libertad procedimental puede ser atenuada por la voluntad de las partes. Si éstas han acordado someterse a ciertas reglas procesales, y el árbitro ha aceptado su función, queda éste obligado a cumplir esas reglas. Esta sujeción se extiende, a nuestro modo de ver, aun a aquellas reglas que el árbitro pueda juzgar incompatibles con la naturaleza de la amigable composición. En un ejemplo extremo, las partes podrían haber pactado arbitraje de amigables componedores, rigiéndose el proceso por las normas previstas para el juicio ordinario. Por más irrazonable que el árbitro juzgue esta decisión de las partes, no puede apartarse de ellas. Por otro lado, fuera del caso en que las partes hayan estipulado reglas específicas para el procedimiento, los amigables componedores deben ejercer con prudencia y discreción sus facultades de crear las reglas a las que se sujetarán las partes y ellos mismos durante el arbitraje. Deberán, en principio, adaptarlas a la naturaleza de la controversia y, en especial, asegurarse de no sorprender a las partes con medidas inesperadas. Ello implica, además, que todo eventual reclamo que realicen las 
partes referido al trato inequitativo o a la imposibilidad de ejercer adecuadamente la defensa deba ser oportunamente satisfecho, en la medida en que ello no implique retrotraer el procedimiento ni exponga a las partes a demoras irrazonables, o a complejidades y costos que no guarden proporción con el monto o con la naturaleza de la disputa.

Llegados a este punto resulta apropiado destinar algunas líneas al trabajo de los abogados litigantes en los juicios de amigables componedores, aclarando que no siempre resulta necesario para las partes contar con asesoramiento profesional. Frecuentemente los abogados en esta clase de juicio incurren en el error de fundar exclusivamente en derecho las pretensiones de sus clientes. Es notorio que tales argumentos y alegaciones sobre la interpretación del alcance de las leyes, que los amigables componedores se encuentran eximidos de aplicar, sólo serán de utilidad para los mismos en forma indirecta y accesoria. Tan así es, que si las presentaciones de ambas partes no mencionaran argumentos en equidad referidos a sus respectivas posiciones, los amigables componedores deberían invitar a ambas partes a expresar sus razones por las que consideran que la posición de su parte consulta mejor la equidad que la posición sustentada por la parte contraria, con independencia de las leyes aplicables. No estamos aquí recomendando a los abogados que omitan toda mención de las normas jurídicas que regirían el caso sino, más bien, que concentren sus argumentos en lo que es esencial e importante para la solución del pleito, es decir, en las reglas de la equidad. Los argumentos que apuntan a demostrar cuál sería la solución legal si el arbitraje fuera iuris en lugar de ser de amigables componedores, incluyendo la cita de precedentes fallados en casos similares haciendo aplicación de la ley, según ya fuera dicho, podrán servir como apoyatura accesoria al debate, pero serán de escasa utilidad para los amigables componedores.

Los reglamentos de arbitraje institucional por lo general no establecen formas distintas ni distinguen entre el arbitraje iuris y el arbitraje de amigables componedores en materia de procedi- 
miento, como sí lo hace el CPCCN. Así, por ejemplo, en ambos casos las decisiones de los árbitros suelen ser en su totalidad inapelables y definitivas.

\section{EJECUCIÓN}

Los laudos de equidad son irrecurribles aun cuando las partes no incluyan una renuncia expresa en la cláusula respectiva (art. 771 CPCCN.) (57). Es posible intentar su impugnación mediante acción de nulidad basada exclusivamente en que el laudo se hubiese pronunciado fuera del plazo fijado (tres meses en ausencia de convención, de acuerdo con el art. 770 CPCCN.), o sobre puntos no comprometidos. Sin embargo, cabe aclarar que existen importantes diferencias entre la demanda de nulidad prevista en el CPCCN. y el recurso de apelación. Entre otras, la relativa al efecto suspensivo que tiene éste y del que carece aquélla (58).

Ello, sin embargo, no impide que en el caso de los laudos extranjeros pueda revisarse la compatibilidad de lo decidido por los árbitros con el orden público internacional del país donde se intenta la ejecución: ésta es una de las causales por las cuales el juez del exequátur puede denegar el reconocimiento del laudo (arts. 517.4 CPCCN. y V.2.b Convención de Nueva York sobre Reconocimiento y Ejecución de Laudos Arbitrales Extranjeros, ratificada por la Argentina mediante ley 23619 [LA 1988 C 3199]).

\section{CONClusiones}

Los autores han enfocado el arbitraje de amigables componedores desde el campo del arbitraje doméstico y con frecuencia han excluido la perspectiva más amplia que se adquiere cuando se analiza la convención de arbitraje desde el punto de vista del 
arbitraje internacional. La ventaja de este perfil es que hace surgir la verdadera esencia de la convención y relativiza las conclusiones a veces dogmáticas de quienes se limitan a comentar las posibles facultades de los amigables componedores según el respectivo Código Procesal local. Surge así la permanente utilidad del arbitraje de equidad como un medio que permite a las partes superar los conflictos entre sistemas jurídicos contradictorios que resulten, según sus propias normas, aplicables al contrato internacional, a los derechos y obligaciones de las partes y a las formas del procedimiento arbitral.

El arbitraje de equidad resulta una herramienta eficaz para fortalecer el laudo y blindarlo contra eventuales impugnaciones que pretendan basarse en errores de derecho o en la inobservancia de formas no esenciales. Permite a las partes buscar soluciones que preserven el contrato en caso de alteraciones en la legislación, cambios en la tecnología o circunstancias de hecho no previstas que, sin llegar a encuadrarse en la tipicidad del caso fortuito, el hecho del príncipe o la fuerza mayor, o en la llamada teoría de la imprevisión (art. 1198 CCiv.), alteren el equilibrio de las prestaciones debidas en perjuicio de una de las dos partes en el contrato.

En contraste con el excesivo rigor de las normas procesales, el arbitraje de equidad recobra el fin último del procedimiento, que es el conocimiento de la verdad de los hechos a fin de concretar efectivamente y en tiempo útil la solución más justa posible del conflicto, con el menor costo para los contendientes. 


\section{NOTAS:}

(1) Los Códigos de Procedimientos provinciales, con ligeras variantes, repiten la distinción entre juicio arbitral y juicio de amigables componedores: Buenos Aires (ALJA 1968-B-1446), art. 804 ;Catamarca (ALJA 1970-B-686), art. 793; Corrientes (LA 2000-B-2403), art. 766 ; Chaco (LA 1999-B-2058), art. 769; Chubut (LA 1983-B-2450), art. 766; Entre Rios (LA 1992-C-4223), art. 795; Formosa (LA 1986-B1910), art. 801; La Pampa (LA 1999-C-3969), art. 743; Mendoza (LA 1993-A-1037), art. 295; Santa Cruz (LA 1981-B-2241), art. 750; Santiago del Estero, art. 785 y Tierra del Fuego (LA 1998-A-1301), art. 741 . Por otro lado, los Códigos de Jujuy, art. 408, y Tucumán (LA 1993-A-1458), art. 452, únicamente admiten el arbitraje de amigables componedores.

(2) Sobre la pericia arbitral remitimos a Caivano, Roque J., "La pericia arbitral y una nueva muestra de la falta de cultura arbitral", JA 2001-I-134; y a Anaya, Jaime L., "La olvidada pericia arbitral", ED 134-605.

(3) El Código de Comercio menciona en varios de sus articulos a "arbitradores" (arts. 128, 156, 158 y 256, entre otros). Para Segovia la palabra "arbitradores", tal como fue usada en nuestro viejo Código de Comercio, sería un "portuguesismo", ya que se trataría en los citados artículos de peritos y no de árbitros, y ciertamente no cabe concluir que los mismos tendrían la misión de emitir laudos según su leal saber y entender. Cita de Segovia, Lisandro, "Código de Comercio", 1892, Ed. Gunche, Weibeck y Turf, nota 446, p. 159 , citado por Jofré, Tomás, "Juicio de árbitros. Competencia", JA 111923-163, n. 16.

(4) Art. 1445 CCom. México (que también recepta la denominación de "árbitros en conciencia"); art. 1019 CPC. República Dominicana. La legislación colombiana sobre mecanismos alternos de resolución de conflictos reserva esta denominación para el mecanismo por medio del cual dos o más particulares delegan en un tercero la facultad de precisar, con fuerza vinculante para ellas, el estado, las partes y la forma de cumplimiento de un negocio jurídico particular (art. 223). 
(5) Art. 626 CPC. Chile (aplicable únicamente a arbitrajes domésticos).

(6) Arts. 19 y 20 Ley sobre Resolución Alterna de Conflictos y Promoción de la Paz Social de Costa Rica; art. 3 Ley de Arbitraje y Mediación de Ecuador; art. 34 Ley de Arbitraje de España (en la exposición de motivos se aclara que las partes pueden pactarlo ya sea a través de una remisión literal a la "equidad" o a términos similares como decisión "en conciencia", ex aequo et bono, o que el árbitro actuará como "amigable componedor"); art. 37 Ley de Arbitraje de Guatemala (aunque alude indistintamente a "arbitraje de equidad", arbitraje ex aequo et bono o "amigable composición); art. 34 Ley de Arbitraje y Conciliación de Honduras; art. 808 CPC. Italia; art. 2 Ley de Arbitraje, Conciliación y Mediación de Panamá; art. 32 Ley de Arbitraje de Paraguay (que también alude a la amigable composición); art. 8 Ley de Arbitraje de Venezuela.

(7) Códigos Procesales de las provincias de Córdoba (art. 633) y Santa Fe (art. 431). A título anecdótico puede señalarse que en el idioma inglés no existe ninguna denominación propia para esta clase de arbitraje. Los textos legales y reglamentarios, la doctrina y la jurisprudencia recurren, alternativamente, a la voz latina ex aequo et bono para calificar la naturaleza de sus decisiones, $o$ a la francesa amiable compositeurs para designarlos. Puede verse: art. 28.3 Uncitral Model Law; art. 33.2 Uncitral Arbitration Rules; art. 17.3 Rules of Arbitration of the International Chamber of Commerce; art. 22.4 London Court of International Arbitration Rules; art. 28.3 New Zealand Arbitration Act 1996; art. 28.3 Commercial Arbitration Act of Canada.

(8) La Ley de Arbitraje de Perú, en su art. 3, lo define como aquel en que los árbitros "resuelven conforme a sus conocimientos y leal saber y entender".

(9) Serantes Peña, Oscar E. y Palma, Jorge F., "Código Procesal Civil y Comercial de la Nación", t. III, 1984, Ed. Depalma, p. 426 y fallos citados en nota 50 .

(10) Art. 54.II Ley de Arbitraje de Bolivia ("...conforme a sus conocimientos y leal saber y entender"); art. 3 Ley de Arbitraje de Ecuador; art. 37.1 Ley de Arbitraje de Guatemala; art. 3 Ley de Arbitraje de Panamá; art. 32 Ley de Arbitraje de Paraguay; art. 24 inc. e Ley de Arbitraje 540 de Nicaragua ("...ex aequo et bono, se da cuando el Tribunal Arbitral resuelve conforme a sus conocimientos profesionales y técnicos"). 
(11) Art. 20 Ley de Arbitraje de Costa Rica; art. 34 Ley de Arbitraje de España; art. 34 inc. b Ley de Arbitraje de Honduras ("...según el sentimiento común y la equidad").

(12) El CPCCN. identifica a la conciliación como un modo "anormal" de terminación del proceso, distinguiéndola de la "transacción". Fuera de que resulta ciertamente sofisticada la diferencia entre ambas figuras, la conciliación podría consistir en un acuerdo de arbitraje a posteriori por el que las partes abandonen la jurisdicción estatal y resuelvan sujetarse a la decisión de un laudo de árbitro o de amigables componedores. Fenochietto considera a la transacción como un contrato con efectos procesales cuando versa sobre derechos litigiosos (Fenochietto, Carlos E., "Código Procesal Civil y Comercial de la Nación, comentado, anotado y concordado con los Códigos provinciales", t. II, 1999, Ed. Astrea, p. 180). La conciliación procesal (en el CPCCN.) es un típico acto procesal celebrado ante el tribunal de la causa en el que el juez o quien lo reemplace puede adoptar una conducta activa proponiendo fórmulas conciliadoras.

(13) La mediación puede ser definida, sencillamente, como una negociación asistida por un tercero neutral llamado mediador. Sobre el tema remitimos a Caivano, Roque J., Gobbi, Marcelo y Padilla, Roberto E., "Negociación y mediación", 1997, Ed. Ad-Hoc. La mediación y la conciliación del art. 309 CPCCN. tienen idéntica finalidad, pero una es realizada por un tercero neutral para prevenir un juicio y la otra es realizada por el juez para poner fin a un juicio ya iniciado. En un sentido más general del término, como el mediador trata de conciliar a las partes, las diferencias entre ambas suelen ser sutiles (Fouchard, Gaillard y Goldman, "International Commercial Arbitration", Gaillard, Emmanuel y Savage, John [eds.], 1999, Ed. Kluwer Law International, La Haya, p. 13).

(14) Ello no impide que el árbitro pueda actuar como facilitador de un acuerdo, del mismo modo que puede hacerlo el juez en el curso de un proceso judicial. Sin embargo, ese doble rol puede presentar complicaciones y, en principio, debe reservarse para casos en que las partes así lo requieran. Ver Gamboa Morales, Nicolás, "Un aporte del arbitraje: las Reglas de la IBA. sobre Recepción de Pruebas en el Arbitraje Comercial Internacional", en Zapata de Arbeláez, Adriana (coord.), "Derecho Internacional de los Negocios", t. II, 2003, Ed. Universidad Externado de Colombia, Bogotá, p. 133 y $5 s$. 
(15) Con anterioridad a la sanción de la ley 24573 (LA 1995-C-3140), que estableció la mediación obligatoria previa a la demanda iniciada ante los tribunales nacionales, podía anotarse como otra diferencia sustancial que mientras que el laudo de un amigable componedor estaba revestido de la calidad de cosa juzgada y su cumplimiento forzado podía perseguirse por los procedimientos de ejecución de sentencia (art. $499 \mathrm{CPCCN}$.), un acuerdo entre las partes no tenía más fuerza obligatoria que la de un contrato, salvo cuando ese acuerdo se hubiese dado en el marco de un proceso judicial y fuera luego homologado por sentencia judicial (en cuyo caso la fuerza de cosa juzgada no emanaba de aquél sino de ésta), o cuando tuviese las caracteristicas de la transacción (conf. art. $850 \mathrm{CCiv.).} \mathrm{Sin}$ embargo, para las mediaciones que se desarrollan bajo el específico marco de esa ley, la norma le atribuye al acuerdo que las partes celebran con la asistencia de un mediador efectos similares a la sentencia (art. 12 párr. $3^{\circ}$ ley 24573), en cuanto a su posible ejecución mediante un procedimiento abreviado. Aun así, ello no implica dotarlo de los efectos de cosa juzgada, que es característica esencial del laudo arbitral.

(16) "Los árbitros proceden y fallan con arreglo a las leyes, como los jueces ordinarios, y los arbitradores en cualquier manera que ellos tengan por bien, con tal que sea de buena fe y sin engaño". (Fallos 22:371, JA 3-348, citado por Jofré, Tomás, "Juicio de árbitros. Competencia" cit.).

(17) Boggiano, Antonio, "El arbitraje y la amigable composición", ED 135-893.

(18) Tal, por ejemplo, lo dispuesto en la Ley Modelo de Arbitraje de Uncitral de 1985 (art. 28.3) y en las legislaciones positivas de Alemania (sección 1058.3); Brasil (art. 11.II); Canadá (art. 28.3); Chile (art. 28.3); Corea (art. 29.3); España (art. 34.1); Francia (art. 1475 del nuevo Código Procesal); Grecia (art. 28.3); Guatemala (art. 37.3); Holanda (art. 1054.3 Código de Procedimiento Civil); Honduras (art. 66); Italia (art. 822 Código de Procedimiento Civil); México (art. 1445 Código de Comercio); Paraguay (art. 32); Perú (art. 117, aplicable al arbitraje internacional); y Venezuela (art. 8). En la legislación boliviana la regla varía según se trate de arbitraje internacional o doméstico: en el primero prevalece el arbitraje de derecho (art. 73.3), mientras que en el segundo la norma de reserva remite al arbitraje de equidad (art. 54.2). 
(19) Así puede verse en los Reglamentos de Arbitraje de la Corte Internacional de Arbitraje de la Cámara de Comercio Internacional (CCL.), art. 17.3; de la Comisión Interamericana de Arbitraje Comercial (CIAC.), art. 33.2 (1978); de la London Court of International Arbitration (LCIA.), art. 22.4; y de la American Arbitration Association (AAA.), art. 28.3. En cambio, la solución del CPCCN. es adoptada por el Reglamento del Tribunal de Arbitraje General de la Bolsa de Comercio de Bs. As. (art. 2). Otras, por fin, sólo prevén el arbitraje de amigables componedores: tal el caso de la Cámara Arbitral de la Bolsa de Cereales de Buenos Aires (Reglamento aprobado por decreto 931/1998). Sobre el funcionamiento de este último tribunal puede verse Caivano, Roque J., "El arbitraje en el comercio de granos", ED 167-826.

(20) "El árbitro no puede instituirse a sí mismo en amigable componedor" (Santos Belandro, Rubén B., "Seis lecciones sobre el arbitraje privado [interno e internacional]", 2002, Ed. Asociación de Escribanos de Uruguay, Montevideo, p. 168).

(21) "La fundamentación según el leal saber es por cierto muy apropiada para el arbitraje pericial que tiene por objeto resolver exclusivamente cuestiones de hecho concretadas expresamente (art. 773 CPCCN.). Y resulta comprensible su razonabilidad en aquella justicia comercial que fue inicialmente de los gremios y corporaciones y se continuó en los consulados, en la que jueces comerciantes resolvian sobre cuestiones inherentes a su propia actividad, bajo las reglas de un derecho oriundo de sus propias costumbres. Pero en el tránsito operado desde el derecho del comerciante individual, o al menos configurado a partir de él, hacia el derecho de los grupos societarios, organizaciones empresarias y negocios de mayor complejidad, la conveniencia del arbitraje librado al leal saber de arbitradores requiere una cuidadosa selección de quienes van a laudar. Sin excluir la conveniencia de los escabinos con relación a ciertas materias, la máxima prudencia aconsejable conduce a la selección de abogados especializados, cuyo saber culto sea una garantía de la solidez jurídica de sus laudos". Anaya, Jaime L., "Equidad y amigable composición", ED 181-548.

(22) En la actualidad la doctrina concerniente a los arbitrajes internacionales considera la posibilidad de negocios o contratos transnacionales desprendidos de todo sistema jurídico, o al menos no comprendidos en un único sistema normativo. Así, el art. 17 
Reglamento CCI. autoriza al árbitro en ausencia de acuerdo a aplicar las normas jurídicas que considere apropiadas y a tener en cuenta las estipulaciones del contrato y los usos comerciales pertinentes. Craig, W. Laurence, Park, William y Paulsson, Jan, "International Chamber of Commerce Arbitration", 2000, Ed. Oceana Publications Inc., Dobbs Ferry, Nueva York, p. 335. También debe mencionarse la importancia que adquieren en el comercio las formulaciones transnacionales como lo son los Principios de Unidroit, del Instituto Internacional para la Unificación del Derecho Privado, 1994, Roma, aplicables cuando las partes hayan acordado que su contrato se rija por ellos.

(23) Zavala Rodríguez, Carlos J., "Código de Comercio comentado", t. I, 1967, Ed. Depalma, p. 559, cometario al art. 448: "Estos árbitros pueden actuar en cualquier manera que ellos tengan a bien, con tal de que sea de buena fe y sin engaño (JA 3-348). Los árbitros de equidad pueden hacerlo todo, excepto negar audiencia adecuada a alguna de las partes. El principio de contradicción (defensa) ha de ser respetado por ellos también, y si no se observa, el arbitraje de equidad será un arbitraje nulo" (citado en C. Civ. y Com. Tucumán, 9/5/1968, "Jiménez de Martínez, Josefina v. Nieto, José M.", LL 184-417).

(24) Deben dejarse a salvo los casos de recurso o demanda de nulidad, los que no se consideran renunciables y mantienen vigente siempre la posibilidad para los tribunales judiciales de control del laudo arbitral. Sin embargo, debe recordarse que en estos supuestos sólo se revisa la validez del laudo, confrontándolo con las causales de nulidad taxativamente previstas por la ley o por los tratados que resulten aplicables.

(25) Existe una diferencia fundamental entre la misión de los árbitros de derecho y los amigables componedores. En este caso las partes voluntariamente se sometieron a juicio de amigables componedores $\mathrm{o}$ arbitradores, $\mathrm{y}$ corresponde que se sujeten a las consecuencias de tal opción. Los amigables componedores son árbitros en equidad y fallan según su ciencia y conciencia, y por ello, salvo en casos extremos en que se habilita la acción de nulidad, el laudo no es revisable por jueces de iure (C. Nac. Com., sala E, 4/4/1989, "Salaberry, G. y otro v. Natalio Alba S.A.", JA 1989-III-514).

(26) "El hecho de que en éste [se refiere al procedimiento] los arbitradores resuelvan según su 'leal saber y entender' no significa que el 
laudo prescinda de aplicar el derecho... la decisión de las causas sometidas a los amigables componedores siempre deberá tener como fundamento el leal saber y entender de letrados, vale decir que deberá integrarse con el saber y entender de hombres versados en derecho". Ver Anaya, Jaime L., "Equidad y amigable composición", ED 181-548.

(27) Anaya, Jaime L., "Equidad y amigable composición" cit.

(28) Aunque en franco retroceso frente a normas de atribución directa de la ley aplicable, muchas leyes y reglamentos aún conservan el sistema de reenvío para determinar la ley aplicable. Las particularidades de estas normas de reenvío también obran como incentivo al arbitraje de amigables componedores, ya que con ellas las partes pueden no tener certeza sobre qué ley regirá finalmente la solución de sus controversias.

(29) Como se ha dicho con acierto, el concepto de equidad se presenta como impreciso, huidizo y controvertido. Mosset Iturraspe, Jorge, "La equidad", revista Tribunales, año II, n. 9, 1988, p. 93, con cita de Lapieza Elli, Ángel, "Aequitas", Anuario de Filosofía Jurídica y Social, p. 2.

(30) Un interesante desarrollo del concepto equidad en la esfera del Derecho Penal puede verse en Fletcher, George P., "Lo justo y lo razonable", 2005, Ed. Hammurabi.

(31) Recasens Siches, Luis en "Enciclopedia Jurídica Omeba", t. X, 1982, Ed. Driskill, voz "equidad", p. 427. Falcón recuerda que equidad viene de aequitas, cuya evolución en el Derecho romano constituyó la adecuación del derecho positivo a los hábitos, costumbres, sentimientos e instintos morales e intelectuales arraigados en la conciencia colectiva (Falcón, Enrique, "Código Procesal Civil y Comercial de la Nación", t. IV, Ed. Abeledo-Perrot, p. 661, comentario al art. 769).

(32) Recasens Siches, Luis en "Enciclopedia Juridica Omeba" cit.

(33) Un excelente trabajo en este sentido puede verse en Pesaresi, Guillermo M., "Apuntes sobre los conceptos, clasificaciones y aplicaciones de la equidad en el Derecho argentino", JA 2005-I-1353.

(34) Vernengo, Roberto J., "Sobre algunas funciones de la equidad", LL $155-1200$. 
(35) De Trazegnies Granda, Fernando, "Arbitraje de derecho y arbitraje de consciencia", rev. Ius et Veritas, Facultad de Derecho de la Pontificia Universidad Católica del Perú, año VII, n. 12, 1996, p. 115 y ss.

(36) Se ha señalado que la equidad aparece como un concepto actualizado, ofreciendo remarcables oportunidades por una nueva concepción de la administración de justicia y del papel del juez. Arnaud, André-Jean, "Consideraciones sobre el juez y la función de juzgar en el siglo XXI", LL Supl. Actualidad del 4/11/2003.

(37) Trib. Arbitraje Gral. Bolsa de Com. Bs. As., "Caja de Valores S.A. v. Lanzillota, Gustavo", LL 1990-B-554. Paulsson, Jan et al., "International Chamber of Commerce Arbitration" cit., ap. 8.05, p. 347. Ello, empero, como se verá, no implica que el amigable componedor debe procurar que la solución satisfaga a las partes, sino que debe atribuir la razón a quien la tiene, en la medida en que él crea que la tiene.

(38) Fouchard, Gaillard y Goldman, "International Commercial Arbitration" cit., p. 840 .

(39) Ver laudo citado supra en nota 37.

(40) Craig, W. Laurence, Park, William y Paulsson, Jan, "International Chamber of Commerce Arbitration" cit., p. 114.

(41) Carnelutti enseñaba que "juicio de equidad" no quiere decir juicio sin regla, porque en tal caso no sería juicio, sino "juicio según una regla que puede ser buscada fuera del derecho, 0 , mejor aún, sobre el derecho". Carnelutti, Francesco, "Instituciones de Derecho Procesal Civil", 1997, Biblioteca Clásicos del Derecho Procesal, México, p. 228.

(42) Sobre el tema puede verse Mustill, Michael, "The new Lex Mercatoria: the first twenty-five years", 1988, Arbitration International, p. 86 y ss. Allí se lo define como un conjunto de principios generales y reglas consuetudinarias, espontáneamente referidas o elaboradas, en el marco del comercio internacional, sin referencia a un particular sistema normativo nacional ("A set of general principles, and customary rules spontaneously referred to or elaborated in the framework of international trade, without reference to a particular national system of laws"). 
(43) Anaya, Jaime L., "Recursos contra los laudos arbitrales", ED 161514.

(44) Craig, W. Laurence, Park, William y Paulsson, Jan, "International Chamber of Commerce Arbitration" cit., p. 110.

(45) C. Nac. Civ., sala F, 3/8/1990, "Bulo, R. v. Comisión Nacional de Vivienda", JA 1991-1I-607; C. Nac. Civ., sala E, 7/4/1997, "Temperato, Francisco y otra v. Belsito, Zulema" y "Belsito, Z. v. Temperato, F. y otro", LL 1997-D-434.

(46) "De donde se desprende que la equidad no puede calificarse como ajena al derecho, especialmente al mercantil" (del fallo citado en nota 37).

(47) Art. 2068 CCiv.: "Cuando las personas se sirvieren del medio de la suerte, no como apuesta o juego, sino para dividir cosas comunes o terminar cuestiones, producirá en el primer caso los efectos de una partición legítima, y en el segundo los de una transacción".

(48) Caivano, Roque J., disertación en las Jornadas Nacionales de Tribunales Arbitrales, Bolsa de Comercio de Rosario, 24 y $25 / 6 / 2004$.

(49) Ley 24240 (LA 1993-C-3012), decreto 276/1998 (LA 1998-B-1523) y resolución SICyM. 212/1998.

(50) Sobre el tema remitimos a Caivano, Roque J., "El arbitraje de consumo en Espan̄a", LL 1996-A-1547; y "El arbitraje de consumo en la Argentina", JA 2003-II-813. Trib. Arbitrales de Consumo, expte. 01220/98, LL 1999-E-491; Trib. Arbitrales de Consumo, 20/10/1998, expte. 0941/98, LL 1999-B-438. Ver.

(51) Corte Sup., "Bruce, David v. De la Carreras, Ernesto", Fallos 22:371, 1880.

(52) A modo de ejemplo, se ha resuelto que ya se trate de árbitros iuris o de amigables componedores, en ninguno de los dos casos quedan excluidas las cuestiones de derecho, que han de ser resueltas -en el segundo caso- "a buena fe guardada y verdad sabida" (C. Civ. y Com. San Isidro, sala 2a , 29/10/1991, "Rodríguez Palacios v. Peña Fernández"). 
(53) Palacio, Lino E., "Otra vez sobre el arbitraje y el control de constitucionalidad", LL 2004-D-19; Morello, Augusto M., "¿Pueden los árbitros declarar la inconstitucionalidad de las leyes?", ED 198-467; Caputo, Leandro J., "Reflexiones en torno a la competencia arbitral para resolver cuestiones constitucionales", JA 2003-II-954 ; Aguilar, Fernando, "Arbitraje internacional: algunas cuestiones prácticas", conferencia pronunciada en el Colegio Público de Abogados de la Capital Federal, 29/5/2003 (la versión corregida por el autor puede verse en http://); Bianchi, Roberto A., "Competencia arbitral para decidir sobre la constitucionalidad", JA 2003-IV-75.

(54) C. Nac. Com., sala E, 11/6/2003, "Otondo, César A. y otro v. Cortina Beruatto S.A. y otros", JA 2003-IV-19, comentado por Bianchi, Roberto A.: "...los árbitros tienen, dentro del marco de lo jurídicamente disponible y efectivamente comprometido, amplia competencia para entender en las cuestiones que les fueron sometidas por las partes, con la facultad implícita de declarar la validez o invalidez constitucional de normas jurídicas".

(55) Art. 769 CPCCN.

(56) Richard, Efrain H., "Arbitraje de derecho", disertación en las Jornadas Nacionales de Tribunales Arbitrales, Bolsa de Comercio de Rosario, 24 y 25/6/2004, y "El arbitraje de Derecho", en .

(57) Anaya, Jaime L., "Recursos contra los laudos arbitrales" cit., ED 161-514. Contra el laudo de los amigables componedores no existe recurso alguno, y la exclusión de los recursos se encuentra compensada por una acción de nulidad que solamente puede sustentarse en que el laudo se pronunció fuera del plazo o sobre asuntos no comprometidos. Sobre el tema puede verse, en extenso, Caivano, Roque J., "Recursos en el arbitraje", Revista de Derecho Procesal, Ed. Rubinzal-Culzoni, n. 2, marzo de 1999, ps. 271/352.

(58) Sobre el tema puede verse C. Civ. y Com. Mar del Plata, sala $2^{\mathrm{a}}$, 9/9/1997, "Schwarzbach, José v. Cappelacci, José", con nota de Caivano, Roque J., "La ejecución de los laudos arbitrales", JA 1998II-30.

$13 / 9 / 2006$ 


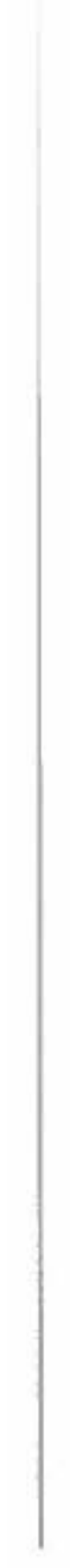

